IBAD Sosyal Bilimler Dergisi

IBAD Journal of Social Sciences

dergipark.org.tr/ibad

IBAD, 2021; (11): 394-412

DOI: $10.21733 /$ ibad.956298

Özgün Araştırma / Original Article

\title{
Endüstri 4.0'ın Turizm Alanındaki Kavramları Üzerine Bir Araştırma
}

\section{A Research On The Concepts of Industry 4.0 In The Field Of Tourism}

Olcay Özışıı Yapıc1 ${ }^{*}$

Gülsün Yıldırım²

\section{* Sorumlu yazar \\ Corresponding author}

${ }^{1}$ Öğr. Gör. Dr., Ondokuz Mayıs Üniversitesi, Türkiye,

Lec. Dr., Ondokuz Mayis University, Turkey

olcay.yapici@omu.edu.tr

ORCID ID 0000-0002-5197-5313

${ }^{2}$ Dr. Öğr. Üyesi, Recep Tayyip Erdoğan Üniversitesi, Türkiye, Assist. Prof. Dr., Recep Tayyip Erdogan University, Turkey, gulsun.yildirim@erdogan.edu.tr

ORCID ID 0000-0001-5299-5722

Makale geliş tarihi / First received : 23.06.2021

Makale kabul tarihi / Accepted : 30.07 .2021

\section{Bilgilendirme / Acknowledgement:}

Yazarlar aşağıdaki billgillen dirmeleri yapmaktadırlar:

1- Araştırmacıların katkı oranı eşittir.

2- Makalenin yazarları arasında çıkar çatışması bulunmamaktadır.

3- Makalemizde etik kurulu izni ve/veya yasal/özel izin alınmasını gerektiren bir durum yoktur. Makale kapsamında etik kurul izni gerektirecek yöntemler kullanılmamıştır.

4- Bu makalede araştırma ve yayın etiğine uyulmuştur.

This article was checked by Turnitin. Similarity Index 06\%

\section{Atıf bilgisi / Citation:}

Özışık Yapıcı, O., Yıldırım, G. (2021). Endüstri 4.0'ın turizm alanındaki kavramları üzerine bir araştırma. IBAD Sosyal Bilimler Dergisi, (11), 394-412 . 
ÖZ

Bilişim ve iletişim teknolojilerindeki gelişmeler ve Endüstri 4.0 ile turizmde akıllı turizm, dijital turizm, turizm 4.0 alan yazında sıklıkla kullanılmaya başlanmıştır. Bu kavramlarla ilgili farklı tanımlar yapilmakta, zaman zaman birbiri yerine kullanılmaktadır. Buradan hareketle bu çalışmada turizmde ortaya çıkan bu kavramların tam olarak neyi ifade ettiği, söz konusu kavramlar kapsamında kullanılan teknolojilerin neler olduğu ve bu kavramlar arasındaki farklılıkların neler olduğu araştırılmıştır. Araştırmada konuyla ilgili alan yazın taranmış, söz konusu kavramlarla ilgili bilgiler ve karşılaştırmalar tablo şeklinde sunulmuştur. Araştırma sonucunda, bu kavramların bir birlerine benzer ve farklı yönlerinin olduğu tespit edilmiştir.

\section{Anahtar kelimeler}

Endüstri 4.0, akıllı turizm, turizm 4.0, dijital turizm.

\section{ABSTRACT}

With the developments in information and communication technologies and Industry 4.0, smart tourism, digital tourism, tourism 4.0 have started to be used frequently in the tourism literature. Different definitions are made about these concepts and they are used interchangeably from time to time. From this point of view, in this study, it is aimed to investigate what exactly these concepts in tourism mean, what technologies are used within the scope of these concepts and what are the differences between these concepts. In the research, the literature on the subject was scanned, information and comparisons about the concepts in question were presented in the form of a table. As a result of the research, it has been determined that these concepts have similar and different aspects to each other.

\section{Keywords}

Industry 4.0, smart tourism, tourism 4.0, digital tourism. 


\section{GíRIŞ}

Sanayi alanında gerçekleşen ilk devrim 18. Yüzyılda 'Buhar Makinesi Dönemi' ile başlamış, ucuz çelik üretiminin yaygınlaştığ 1860 ' 1 yıllarda da İkinci endüstri devrimi ortaya çıkmıştır. Seri üretimin elektrik ile yapıldığı dönem de Endüstri 3.0'ın başlangıcı olarak kabul edilmiştir. Bilişim ve iletişim teknolojilerindeki gelişmeler ve bu gelişmelerin üretime yansıması Endüstri 4.0'ın ortaya çıkışını desteklemiştir (Banger, 2018).

Endüstri devrimleri ile birlikte insan yaşamında büyük değişiklikler yaşanmaktadır (Akkuşçu, 2019). İçinde bulunduğumuz endüstri 4.0'1n oluşumunda bilgi ve iletişim teknolojilerinin kullanımı oldukça etkilidir. İlk olarak 2011 yılında kullanılan Endüstri 4.0'ın en çok etkilediği alanlardan birisi de turizm endüstrisidir. İnternetin kullanımının yaygınlaşması, bilgi ve iletişim teknolojilerinin yaygınlaşması ve Endüstri 4.0 ile birlikte nesnelerin interneti, büyük veri, yapay zeka, sensörler gibi yeni nesil teknolojiler söz konusu olmuştur. Endüstri 4.0 ile iş yapma, iletişim kurma, eğitim alma, tatil planlama gibi faaliyetler oldukça hızlı gelişme göstermiştir. Dolayısı ile ülkeler, yönetimler, insanlar da endüstri 4.0'a ayak durmak durumunda kalmıştır (Kemer, 2021; Karaman ve Sayın, 2019; Mil ve Dirican, 2018).

Endüstri 4.0'1 destekleyen birçok teknolojik gelişme (Nesnelerin interneti, arttırılmış gerçeklik, bulut bilişim, robot teknolojiler vb.) yaşanmış (Hermann, Pentek ve Otto, 2016) ve bu teknolojiler birçok sektörde kullanılmaya başlanmıştır. Bu sektörlerden biri de turizmdir. İnternetin yaygın kullanımı, teknolojinin gelişmesi, endüstri 4.0 devrimi ile birlikte akıllı turizm, dijital turizm, turizm 4.0. kavramları alan yazında yer almıştır. Nesnelerin interneti ve dijital dönüşümün, turizmde 'akıllı' akımını ortaya çıkarmasıyla (Çetinkaya, 2019), turizmde 'Akıllı turizm', 'akıllı destinasyon', 'dijital turizm', 'turizm 4.0' gibi birçok kavram, yapılan bilimsel çalışmalarda sıklıkla birbiri yerine kullanılmaya başlanmıştır. Bu kavramlarla ilgili farklı tanımlar yapılmakta, zaman zaman birbiri yerine kullanılmaktadır. Buradan hareketle bu çalışmada turizmde ortaya çıkan bu kavramların tam olarak neyi ifade ettiği ya da bu kavramlar arasındaki farklılıkların neler olduğu araştırılmıştır.

\section{ENDÜSTRI 4.0 VE TURİZM}

\section{Endüstri Devrimleri}

Sanayi Devrimi; 18.yüzyılın sonralarından 19. Yüzyıla kadar uzanan ve küçük atölyelerin daha büyük ölçekli üretim yapan endüstriyel işletmelere dönüşmesidir (Frederick, 2016, s.9). Birinci Endüstriyel Devrim 18. Yüzyılın sonunda su ve buhar enerjili mekanik üretim tesislerinin devreye girmesiyle başlamıştır. Bu aşamada sanayi, el işçiliğinden makine ve buhar kullanımına geçmiştir. İkinci Endüstriyel Devrim ise 20. yüzyılın başında işbölümüne dayalı elektrik enerjili kitlesel üretimin devreye girişi ile başlamıştır. Bu devrimde seri üretim ve elektriğin yaygınlaşması söz konusudur. 3. Endüstriyel devrimde, 1970'lerin başında imalatın otomasyonunu ileri safhalara taşımayı başaran elektronik ve bilgi teknolojileri (ilk mikro bilgisayar; Apple I) etkili olmuştur. Günümüzde, siber-fiziksel sistemlere dayalı üretim ile 4. Endüstriyel devrimden bahsedilmeye başlanmıştır. Her ne kadar Endüstri 4.0 üçüncü devrimin uzantısı olarak görenler olsa da bu devrimin farklılıkları bulunmaktadır (Verl, 2017). Endüstri 4.0 kendi üretimini, kapasitesini ve tedarik zincirini planlayabilen yeni nesil endüstri olarak da tanımlanmaktadır. Bu sanayi devriminde; makineler arası iletişim, yapay zeka, nesnelerin interneti, bulut bilişim, büyük veri, sanal ortamlar, otonom makineler, hücresel taşıma sistemi gibi teknolojilerin fiziksel sanayi unsurları ile birleşmesi söz konusudur. Ayrıca, 
değer zincirindeki her bir unsurun otomasyon sistemi içerisinde olması gerekmektedir (Özdoğan, 2017, s.1; Firat ve Firat, 2017, s. 212).

\section{Endüstri 4.0}

2011 yılında Almanya Eğitim Araştırma Bakanlığının oluşturduğu projelerden biri olan Endüstri 4.0 ilk kez Hannover Fuarı'nda dile getirilmiştir (Fang, 2016; MacDougall, 2013). Gelişen teknolojiler ve iletişim kolaylıkları ile hammadde ve pazarlara ulaşım kolaylaşmıştır. Dolayısı ile üretim ve talep doyum noktasına ulaşmış ve küreselleşme ile birlikte rekabet de artmıştır. Bu rekabet de gelişmiş bazı ülkeleri, maliyetleri düşürmek için arayışlara sevk etmiştir. Bu ülkeler üretimlerini öncelikle işgücü maliyetinin düşük olduğu ülkelere yöneltmişlerdir. İşgücü maliyetlerinin düşük olduğu ülkelerden olan Çin, Hindistan ve Brezilya gibi ülkeler elindeki ürünleri yenileyerek, sanayi devlerinin arasında yer almayı başararak rekabet savaşına katılmıştır. Rekabetin bu denli artmasıyla Almanya öncülügünde gelişmiş ülkeler emek maliyetlerini düşürmek, az nitelikli işgücüne olan bağımlılı̆̆ı azaltmak için Dördüncü Sanayi Devrimini başlatmışlardır. Endüstri 4.0'ın gerek duyulmasının nedenlerinden bir diğeri de değişen tüketici talepleri olduğu ileri sürülmektedir. Tüketicilerin yeni ürünlere hızlı ulaşma isteği ve bireyselleşen müşteri istekleri Ensdüstri 4.0'ın bir ihtiyaç olarak görülmesine neden olmuştur. İşletmeler yeni ürünleri daha hızlı piyasaya sunma ve bireyselleştirilmiş ürün sunma becerileri arttırma adına bazı çabalar içine girmiştir (Pamuk ve Soysal, 2018, s. 4-5). Rekabetin artması, maliyetleri azaltma gereksinimi, kaynakların tükenmesi, piyasaya hızlı ve hatasız ürün çıkarabilmek ve az nitelikli işgücüne olan bağımlılığı azaltmak gibi nedenler Endüstri 4.0'ın gelişimini tetiklemiştir (Şekkeli ve Bakan, 2018; Pamuk ve Soysal, 2018). Dördüncü Sanayi Devrimi'nin amaçlarını gerçekleştirebilmesi için birtakım araçlara ihtiyacı vardır. Bu araçlar sayesinde bilgi ağını ve haberleşmeyi geliştirerek bahsedilen amaçlara ulaşılabilir.

\section{Endüstri 4.0'1 Destekleyen Teknolojiler}

Endüstri 4.0'1 destekleyen önemli teknolojiler arasında iş birlikçi robotlar, akıllı fabrikalar, arttırılmış ve sanal gerçeklik, endüstriyel robotlar, nesnelerin interneti, siber fiziksel sistemler, yapay zekâ sensörleri, 3D yazıcılar, büyük veri, bulut bilişim, giyilebilir teknolojiler, öğrenen robotlar, akıllı sinyalizasyon, kuantum bilişim ve nano teknolojiler yer almaktadır (Özdoğan, 2017; Karaman ve Sayın, 2019; Hermann, Pentek ve Otto, 2016).

İlk olarak 1999 yılında Kevin Ashton tarafından literatüre giren nesnelerin interneti (IoTInternet of Things), "akıllı" olarak tanımlanan gerçek nesneleri ve yerleri tanımlamak, bulmak, yönetmek ve izlemek için her zaman ve her yerde her şeyi bağlayabilen bir ağ olarak tanımlanmaktadır (Ashton, 2009). Sensörler, erişim düzenekleri, biochipler, izleme cihazları nesnelerin interneti kavraminda 'nesne' olarak kabul edilmektedir. Bir cihazın nesne olabilmesi için bir sensörünün olması, tek bir kimliğe (unique ID) sahip olması ve bağlanabilir olması gerekmektedir (Karaman ve Sayın, 2019).

Sanal gerçeklik, "kişinin üç ve çok boyutlu bilgisayar ortamına girdiğinde dışarıdaki dünya ile ilişkisinin koptuğ ortamlar", artırılmış gerçeklik ise "sanal ve gerçek nesnelerin birlikte hissedildiği, görselliğin ve verilerin gerçek ortama eklenebildiği, girilen sanal ortama rağmen bunlarm birlikte alğlandığı durumlar" olarak tanımlanmaktadır (Bal ve İçten, 2017, s.111). Artırılmış gerçeklikte, gerçek dünya canlandırılmakta iken, sanal gerçeklikte, gerçek dünya yerine tasarlanıp canlandırılmış bir dünya bulunmaktadır (Sunar, Ateş ve Akmeşe, 2019). 
Siber fiziksel sistemler, internet üzerinden ve bir internet adresi aracılığı ile haberleşen bir ağ ve gerçek dünyadaki olguların simülasyonu ile ortaya çıkan sanal ortam olmak üzere iki önemli unsurdan oluşan sanal dünya ile fiziksel dünyayı birbirine bağlayan uygulamalardır (Özsoylu, 2017). Teknolojik gelişmeler ile tüm endüstri ve iş kollarında robotlar kullanılmaya başlanmıştır. 1995 yılında akıllı robot olarak da bilinen Cobot kavramı kullanılmaya başlanmıştır. Bu akıllı robotlar, iş ortamında insanlarla iletişime giren, insan gibi düşünen, insan gibi davranan ve koordineli çalışabilen yapay zekaya sahip bilgisayarlar olarak da ifade edilmektedir (Alexis, 2017). Hem hizmet hem de sosyal alanlarındaki faaliyetlerine göre robotlar; hizmet robotu, kişisel hizmet robotu, profesyonel hizmet robotu şeklinde sinıflandırılmaktadır (Pieska, Luimula, Jauhiainen ve Spiz, 2012).

Hacmi sürekli artan, daha yüksek hıza ve çeşitliliğe sahip veri setleri de büyük veriyi oluşturmaktadır. Birçok farklı kaynaktan elde edilen veriler amaca uygun ve doğru şekilde analiz edildiğinde işletmeler için büyük bir fırsat ve rekabet üstünlüğü yaratacaktır (Soydaş ve Saçlı, 2019). Endüstri 4.0’1 destekleyen bir diğer teknoloji ise bilgisayar aracılığı ile elde ettiği veriyi somut nesneye dönüştüren 3D yazıcılardır. 3D yazıcıların yanı sıra uzakta konumlandırılmış bilgisayarlara İnternet üzerinden erişilerek; verilerin saklanması, işlenmesi ve kullanılmasını sağlayan (BTK, 2013) bulut bilişim de Endüstri 4.0'1 destekleyen teknolojiler arasindadir.

\section{Endüstri 4.0 ve Turizm}

Endüstri 4.0'1n turizm sektöründe önemli etkileri olmuştur. Özellikle turist beklentileri, memnuniyeti ve tercihleri gibi konularda büyük verilerin kullanımı ile düşük maliyetli kişiye özel hizmet geliştirilmeye başlanmıştır. İnternet, web teknolojileri ve mobil uygulamalardaki gelişmeler turizm işletmelerinin maliyetlerinin azalmasında etkili olmaktadır (Sayın ve Karaman, 2019). Üç boyutlu sanal gerçeklik uygulamaları ile turistler ören yeri, müze, otel işletmesi gibi yerleri ziyaret edebilmektedir. Turizm işletmelerinin tanıtımları arttırılmış gerçeklik ve hologram sayesinde yapılabilmekte ve turistler ürünü satın almadan önce deneyimleme fırsatı bulmaktadır. Hatta Endüstri 4.0'1 destekleyen teknolojilerden biri olan robotlar turizm işletmelerinde (Otel, restoran vb.) kullanılmaya başlanmış ve tüm çalışanların robot olduğu Henn An Otel 2015 yılında faaliyete geçmiştir (Osawa, Ema, Hattari, Akiya, Kanzaki, Kubo, Koyama ve Ichise, 2017).

\section{-Bulut Bilişim ve Turizmde Kullanımı}

Bulut teknolojileri turizm işletmelerinde e-ticaret, bilgi işlem alt yapılarının oluşturulması, pazarlama, satış, rezervasyon, kat hizmetleri yönetimi, konaklayan misafir bilgi yönetimi, idari ofis uygulamaları, restoran ve banket yönetimi, misafire yönelik arayüz uygulamaları (çağrı kayıt sistemi, yardımcı misafir hizmetleri vb.) gibi alanlarda yoğun olarak kullanılmaktadır. Turistler bulut bilişim sayesinde otele gelmeden önce odasını kontol edebilir, spa randevusu alabilir, özel promosyon veya teklifleri görüntüleyebilir (Yazıcı ve Ayazlar, 2019).

\section{-Arttırılmış Gerçeklik ve Turizmde Kullanımı}

Arttırılmış gerçeklik turizmde farklı alanlarda kullanılmaktadır. Müzelerde, kültürel miras alanlarında, konaklama işletmelerinde, yiyecek içecek işletmelerinde (yemeğin hazırlanışı, içindeki malzemeler, kalori hesaplama vb. özellikleri üç boyutlu inceleyebilme), GPS'li 
haritaların ve sanal yolların hazırlanmasında arttırılmış gerçeklik kullanılmaktadır (Sunar, Ateş ve Akmeşe, 2019).

\section{$\underline{\text { Nesnelerin İnterneti ve Turizmde Kullanımı }}$}

RFID teknolojisi ile turistlerin takip edilmesi, Akıllı chip ile turistlerin takip edilerek turistik faaliyetlerin istatistiklerin tutulması, WSN ile destinasyona giriş yapan turist sayısının hesaplanması, ONS ile tüm tesislerden bilgi toplanılması ve turistlere en iyi tesisler ile ilgili bilgi verilmesi, EPC ile turistlerin ortak ilgi alanlarına sahip gruplara kayıt olmasının sağlanması, kablosuz iletişim teknolojisi ile turistlere geri bildirim verilmesi (Babu ve Subramoniam,2016) gibi IoT teknolojilerinin turizmde kullanım alanları vardır.

\section{Büyük Veri ve Turizmde Kullanımı}

Büyük veri; turizm talebini tahmin etme, kişiselleştirilmiş turistik ürün tasarlama, turist memnuniyetini ölçme, iş modeli ve stratejisi oluşturma, turistlerin dijital ayak izlerini izleyebilme gibi alanlarda turizm sektörüne katkı sağlamaktadır.

\section{Blok Zincir Teknolojisi ve Turizm}

Turizmde blok zincir teknolojisi; turist deneyiminin anlık takibinin yapılması, aracısız çalışma ortamının sağlanması, turizm sektörüne yönelik sadakat programlarının tasarlanması, çevrimiçi müşteri yorumlarının takibi, ülke sınırları ve paydaşlar arası güvenli para transferi, bagaj takibi gibi birçok alanda kullanılmaktadır (Gülcemal, Sayın ve Karaman, 2019).

\section{$\underline{\text { Robot Teknolojiler ve Turizmde Kullanımı }}$}

Endüstri 4.0 ile birlikte robot teknolojileri (robot rehber, robot aşçı, robot garson vb.) ile daha sık karşılaşılmaya başlanmıştır. Türkiye'de ilk robotlu kafe Konya'da açılmıştır (Sağır ve Oraç, 2019). Otel işletmelerinde ön büro, yiyecek içecek, kat hizmetleri ve bar bölümlerinde robotların kullanıldığı görülürken, havaalanlarında da robotlardan faydalanılmaya başlanmıştır. Robotlar artık turist rehberliği, yol tarifi, yemek yapımı, yiyecek- içecek servisi, oda temizliği, sipariş alma gibi birçok iş için kullanılmaya başlanmıştır (Mil ve Dirican, 2018).

\section{ARAŞTIRMANIN AMACI VE YÖNTEMI}

Endüstri 4.0 ile turizm alanında akıllı turizm, turizm 4.0, dijital turizm kavramları sıkça kullanılmaya başlanmıştır. Bu kavramların zaman zaman birbiri yerine kullanıldığı ve kavram karmaşasına yol açtığı da görülmektedir. Dolayısı ile teknolojik gelişmelerle turizmde ortaya çıkan bu kavramların tam olarak neyi ifade ettiği ya da aralarındaki farklılıkların neler olduğunun bilinmesi gerekmektedir. Buradan hareketle bu araştırmada Endüstri 4.0 ile turizm alanında ortaya çıkan 'Akıllı Turizm, Dijital Turizm, Turizm 4.0' kavramların alan yazın bağlamında incelenmesi hedeflenmiştir. Alan yazın taraması için 'google scholar' veri tabanı kullanılmış ve Endüstri 4.0 ile turizm alanında kullanılan 'Akıllı Turizm, Dijital Turizm, Turizm 4.0' kavramları bu veri tabanına girilerek bu kavramlarla ilgili yapılan çalışmalar (kitap, makale, bildiri) tek tek taranmıştır. Google scholar veri tabanına Akıllı Turizm yazıldığında 18 adet çalışmaya, Dijital Turizm yazıldığında 7 adet çalışmaya, Turizm 4.0 yazıldığında ise 4 adet çalışmaya ulaşılabilmiştir. Söz konusu kavramların isminin geçtiği çalışmalarda hangi teknolojilerden yararlanıldığına hazırlanan tabloda yer verilmiştir. Çalışma kavramsal incelemeye dayanan bir derleme niteliğindedir. Makalelerde söz konusu kavramların nasıl tanımlandığı, hangi teknolojilerin kavram içerisinde kullanıldı $\breve{g}_{1}$, bahsi 
geçen teknolojilerin turizm sektöründe hangi alanda kullanıldığına ilişkin genel bir bakış açısı oluşturulmuştur. Ayrıca çalışma etik kurul gerektirmemektedir. Bu çalışma, Türkçe yapılan çalışmalar içerisinde akıllı turizm, dijital turizm ve turizm 4.0 kavramları kapsamında incelenen teknolojiler ve kullanım alanlarının bir arada değerlendirilmesi açısından önem arz etmektedir.

\section{ENDÜSTRİ 4.0'IN TURİZM ALANINDA ORTAYA ÇIKARDIĞI KAVRAMLAR}

\section{Ak1llı Turizm}

Endüstri 4.0’ın insan hayatına girmesi ile birlikte akıllı kavramını pek çok yerde görmek mümkündür. Akıllı kelimesinin kendine yer edindiği alanlardan birisi de turizm sektörüdür. Turizm sektörünün merkezinde insanın yer alması nedeniyle her daim yeniliklere ihtiyaç duyulmaktadır (Şimşek ve Cinnioğlu, 2020, s. 677). Bilgi ve iletişim teknolojilerinin yaygınlaşması ile birlikte akıllı turizm kavramı daha yaygın bir şekilde kullanılmaktadır. Akıllı kavramı Türk Dil Kurumu tarafından 'gerçeği iyi gören ve ona göre davranan, akil' şeklinde tanımlanmaktadır (TDK, 2021). Akıllı kelimesinin İngilizce karşılı̆̆ smart olarak kullanılmaktadır. Smart kelimesinin anlamı ise İngilizce tanıma göre deneyim, bilgi ve iyi muhakeme sahibi olmanın kalitesi şeklinde tanımlanmaktadır. Smart tourism ile intelligent tourism kavramları birbirine benzer kavramlar gibi görünmektedir. Intelligent kelimesi anlam olarak değişen durumlara, farklılaşan gereksinimlere, önceki deneyimlere ayak uydurabilen değişimi sağlayabilen şeklinde kullanılırken Smart kelimesi ise karmaşık durumlarda doğru olan, büyük veri gerektiren içeriği daha büyük olan kavramdır. Intelligent kelimesi zeka olarak kullanımla birlikte teknolojinin alanına girmektedir ancak smart kelimesi ise insanlar için ortaya çıkan teknolojik sonuçlara odaklanmaktadır (Li, Hu, Huang ve Duan, 2017: 294). Akıllı kelimesi sensörler, büyük veri, açı veri, yeni iletişim yöntemleri ve bilgi alışverişi teknolojilerinin ortaya çıkardığı çok sayıda disipline hakim olan bir kelime olarak tanımlanmaktadır (Gretzel, Werthner, Koo ve Lamsfus, 2015).

Akıllı kavramının turizmde kullanımı başlangıçta destinasyonlar için kullanılarak yaygınlaşmaya başlamıştır (Cabi ve Erbaşı, 2019, s. 30). Akıllı turizm kavramının alanda yer alması ilk defa Buhalis ve Amaranggana $(2014,2015)$ tarafından gerçekleştirilmiştir. Akıllı turizm kavramı akıllı teknolojilerin turizmde kullanılmasını kapsamaktadır (Gretzel, Sigala, Xiang, ve Koo, 2015, s. 179). Yalçınkaya, Atay ve Karakaş (2018) akıllı turizm kavramını akıllı turistik deneyimlerin oluşturulması, sunulması ve yönetilmesi için turizmde bilgi ve iletişim teknolojileri ile akıllı teknolojilerin kullanılması şeklinde tanımlamışlardır. Akıllı turizm kavramı, bilgi ve iletişim teknolojilerinin kullanımının yanı sıra turizm yönetimine farklı bir bakış açısı sunmaktadır (Cabi ve Erbaşı, 2019, s. 30). Akıllı turizm kavramı ile bütünleşen teknoloji bireysel olmaktan ziyade alt yapı olarak kullanılması ve turizmle ilgili iş süreçleri ve performansların iyileştirilmesini sağlayarak alternatifler arasında en akıllı olanın seçilmesine yardımcı olarak gerçek dünya hakkında gerçek zamanlı farkındalık oluşmasını sağlayan akıllı bilgi işlem teknolojilerinden oluşmaktadır (Gretzel ve diğ. 2015, s. 182). Akıllı turizmdeki temel amaç, sürdürülebilirlik çerçevesinde rekabet koşullarını iyileştirerek turist deneyimlerinin gelişmesi ve memnuniyetin en üst seviyelere çıkmasıdır (Buhalis ve Amaranggana, 2014, s. 553-564). Akıllı turizmin ne olup ne olmadığı konusunda alan yazında iki farklı görüş söz konusudur. Akıllı kavramı ilk olarak bilgi ve iletişim teknolojilerindeki gelişim ile ilişkili olması yönündedir. Bu bağlamda akıllı teknolojiler destinasyonların yönetiminde, turistik etkinliklerde, konaklama işletmelerinde etkili bir araç olarak görülmektedir. Bilginin 
toplanması, analiz edilmesi ve dağıtılması şeklindeki süreç, büyük verilerin kullanımı, birbirine bağlı araçlar ve yapay zeka araçları akıllı yönetim uygulamalarının merkezinde yer almakla birlikte internet ile gerçekleşmektedir. İkinci bakış açısı ise insanların akıllı kaynakları nasıl kullandığı ve akıllı kaynakların sürdürülebilirliği ile ilişkilidir (Mehraliyev, Choi ve Köseoğlu, 2019, s. 523). Her iki bakış açısının toplamı olarak akıllı turizm kavramı fiziksel alt yapı, sosyal bağlantılar, yönetim kaynakları, insan zihninin birleşmesi ile gelişmiş teknolojilerin kullanımına yönelik çabaları ile sürdürülebilirlik ve verimliliğin sağlanmasına yönelik iş süreçlerini kapsayan destinasyondaki bütünleşik çabalardır (Gretzel ve diğ., 2015, s. 181). Tanımlardan anlaşılacağı üzere akıllı turizm kavramı merkezinde sürdürülebilirlik felsefesinin var olduğu, endüstri 4.0'ın sunmuş olduğu bilgi ve iletişim teknolojilerinin turizmin her seviyesinde kullanılması ile işletmeler açısından en iyi performansın sergilendiği ve verimliliğin üst düzey olduğu, sonucunda ise turistin memnuniyetinin en üst seviyede olduğu turizm sistemini kapsamaktadır.

Akıllı turizm, geleneksel turizm ve zemininde teknoloji odaklı inovasyonun olduğu e-turizmin (elektronik turizm) olduğu mantıklı evrimsel bir gelişmedir (Gretzel ve diğg., 2015). Akıllı turizm kavramı gerek vatandaşların gerek turistlerin hareketliliğini kapsaması, kaynakların sürdürülebilir şekilde kullanımı, yaşam ya da ziyaret kalitesini dikkate almasından ötürü akıllı destinasyon olarak da tanımlanmaktadır (Çelik ve Topsakal, 2017, s. 154). Akıllı turizm kavramı akıllı şehir bileşenleri ile bağlantılıdır. Akıllı şehir bileşenleri ise akıllı yönetim, akıllı çevre, akıllı hareketlilik, akıllı insanlar, akıllı ekonomi ve akıllı yaşam şeklindedir (Cohen, 2012). Akıllı yönetim verilerin açık bir şekilde elde edilmesi ile yönetimin şeffaflı̆̆ını, akıllı çevre sürdürülebilir enerji kullanımını, akıllı hareketlilik gerek şehirlerarası gerek şehir içinde erişilebilir ulaşım sistemlerini, akıllı insanlar şehir insanlarının niteliğini, akıllı ekonomi teknoloji odaklı ekonomik sistemlerin varlı̆̆ını, akıllı yaşam ise sosyal anlamda yüksek yaşam kalitesine ilişkin uygulamaları kapsamaktadır (Buhalis ve Amaranggana, 2014, s. 555). Turizm ile ilişkili verilerin toplanması toplanan verilerin işlenmesi ve kullanımı akıllı turizmin fonksiyonları arasında yer almaktadır. Toplanan, işlenen veriler aracılığı ile akıllı deneyim, akıllı iş çevresi, akıllı destinasyon olan akıllı turizmin bileşenlerini oluşturmaktadır (Gretzel ve di ğ., 2015).

Akıllı turizm bir destinasyona ek olarak turizm deneyiminde bilgi ve iletişim teknolojilerinin bir arada kullanılması ile ortaya çıkan sosyal bir olgudur. Akıllı deneyim bileşeni teknoloji odaklı turizm deneyimi ve bu deneyimin gerçek zamanlı kişiselleştirilmesidir. Akıllı turizm deneyiminin temel gücü bilgi toplama, her an internete bağlllık, gerçek zamanlılık şeklindedir ve dolayısı ile akıllı turizm deneyimi verimliliği ve anlam bakımından zenginliği kapsamaktadır. Turistler aktif katılımcı konumundayken tüketim yaparken diğer taraftan da veri zenginliğinin oluşmasını sağlamaktadırlar. Akıllı turistler deneyimlerine değer katmak amacıyla akıllı telefon kullanarak internetin sağladığı imkanlardan yararlanmaktadır. Üçüncü bileşen olan akıllı iş çevresi turistik kaynakların değişimi ve turizm deneyiminin birlikte oluşumunu desteklemektedir. Akıllı iş çevresi dinamik olarak birbirine bağlı paydaşlar, iş süreçlerinin dijitalleşmesi, örgütsel uyum olarak akıllı turizm kavramında yer almaktadır. Akıllı iş çevresi içerisinde kamu ve özel sektöründe iş birliği oldukça önemlidir (Gretzet ve diğ., 2015).

Akıllı turizm, nesnelerin interneti, mobil iletişim, bulut bilişim ve yapay zeka olmak üzere dört temel teknolojiden oluşmaktadır. Nesnelerin interneti, zaman, mekan ve varlığa ilişkin bir 
sınırlama olmaksızın her şeyin birbirine bağlı olma durumudur (Çelik ve Topsakal, 2019, s.1624). Cep telefonları, mobil cihazlar, sensörler ya da çipler gibi nesneler ile internete bağlı olma sonrasında gerçek dünya ile sanal dünya arasındaki fark ortadan kalkmaktadır. Nesnelerin interneti aracılığı ile çeşitli bilgilerin toplanabileceği platformların oluşturulması mümkündür (Gretzet ve diğ., 2015). Starwood ve Hilton gibi otellerde kullanilan mobil uygulama ile müşteriler odalarının hazır olduğunu öğrenebilmekte, oda girişinde telefonlarını okutarak kapı kilidini açabilmekte ve hatta uygulama ile oda rezervasyonu yapabilmektedir. Mobil iletişim akıllı turizmin kullanmış olduğu bir diğer teknolojidir. Akıllı telefonlar, GPS, tabletler bilgisayarlar, dizüstü bilgisayarlar mobil iletişim araçları olarak kullanılmaktadır. Bulut bilişim ise kamunun kullanımına sunulan iletişim ağı ile güvenilir platformlardan veri depolama imkanı sunan teknolojidir (Masseno ve Sanstos, 2018). Önbüro uygulamalarında, restoran yönetiminde, seyahat acentacılığında ve turistin deneyimine ilişkin çok sayıda alanda bu teknolojilerden yararlanılabilmektedir (Yazıcı ve Ayazlar, 2019). Yapay zeka teknolojisi ise bilgisayar sistemlerine deneyimlerden otomatik olarak yararlanma firsatı veren, verimliliği artırarak insan gibi günlük görevleri yerine getirebilecek özelliğe sahip insan zekasının simülasyonudur (Li, Bon ve Ye, 2019). Çevrim içi seyahat acentelerinin Chatbotlar aracılı̆̆ ile rezervasyon yapması, otellerde robotların kullanımı, mutfakta robotlardan yararlanma yapay zeka uygulamalarına örnek olarak gösterilebilir.

\section{Dijital Turizm}

Dijital kavramı Fransızca kökenli bir kavram olmakla birlikte Türk Dil Kurumu tarafından "sayı ile ilgili, sayı temeline dayalı, sayısal" olarak tanımlanmaktadır (TDK, 2021). Dijital kavramının tarihine bakıldığında 1 ve 0 rakamlarından oluştuğu ve 17. yüzyılda ortay çıktığ1 görülmektedir. Bilişimde 1 bir şeyin var olduğunun göstergesi iken 0 ise olmadığının göstergesidir. 1 ve 0 bit olarak adlandırılmaktadır. Bilgi depolama yaklaşımlarının geliştirilmesinin ardından bilişim sektörünün temelleri atılmıştır (Aksu, 2018). Dijitalleşme ilk olarak bilgi teknolojileri alanında ortaya çıkmıştır. Dijitalleşmenin tanımında bir işin (metin, resim, ses gibi) bilgisayar tarafından okunabilir, şifrelenmiş farklı bir medyaya sayısallaştırılarak dönüştürülmesidir. Dijitalleşme her işletme için farklı adımlardan oluşan birbirine bağlı çok sayıda süreci kapsamaktadır. Dijitalleşme iş modelinin değişmesine yardımcı olan, yeni bir değer yaratan dijital teknolojilerin kullanımını kapsamaktadır. Dijitalleşme modern bilgi teknolojilerinin turizmde kullanımı ile ortaya çıkmaktadır (Happ ve Horvath, 2018, s. 10). Bilişimdeki gelişmeler ve internet hem turistlere hem de destinasyonlara iletişim sürecinde yeni kanallar oluşumunu sağlarken arama ve dağıtım maliyetlerini de azaltmıştır (Buhalis, 2003).

Dijital turizm, turist deneyiminin zenginleştirilmesinde dijital teknolojilerin kullanılması olarak tanımlanmaktadır (Adeola ve Evans, 2019, s.190). Özellikle son yıllarda gelişmiş ülkelerde cep telefonları ve internet dijital seyahat devrimini gerçekleştirerek turizm endüstrisini dönüştürmektedir (Law, Chan, ve Wang, 2018). Dijital turizm, turizm deneyimlerinin dijital araçlar ile desteklenmesi ile ilgilidir. Dijital turizmde yeni olan şey aslında turizmin dijital olarak gelişmesidir. Teknolojinin kullanımı ile kalitenin artması ya da turist deneyiminin iyileştirilmesi hedeflenmektedir. Seyahat rezervasyonlarını daha kolay yapabilmek, basılı bir rehber yerine multimedya rehber kullanmak gibi işlemler turistin deneyimini önemli ölçüde etkilemektedir (Benyon, Quigley, O'keefe ve Riva, 2013). Dijital turizm destinasyonlarda müzeler, hayvanat bahçesi, kırsal kesimler, tema parklar gibi farklı 
mekanlara odaklanmaktadır (Durrant, Golombewski, Kirk, Benford, Fisher, Rowland ve McAuley, 2011). Tasarımcılar ve araştırmacılar interaktif haritalar, asistanlar, ilgi noktaları, hediyelik eşya noktaları gibi turistin deneyimini etkileyecek çok sayıda farklı ve çeşitli araç gereç oluşturmuşlardır. Bu araç gereçler dijital turizm alanının oluşumunda tasarım tekniği olarak kullanılmaktadır (Benyon ve diğ. 2013).

Dijital kavramı turizmde yaygın olarak dijitalleşme şeklinde kullanılması daha uygun olmaktadır. Dijitalleşme, modern bilgi teknolojilerinin turizmde kullanımı olarak tanımlanmaktadır (Happ ve Horvath, 2018). Turizmde dijitalleşme kavramı ise yaygın olarak pazarlama karması elemanlarının kullanımında gerçekleşmektedir. Turizmde dijitalleşme üzerine yapılan çok sayıda çalışma mevcuttur. Bağçı ve İçöz (2019) tarafından yapılan çalışmada dijitalleşen turizm ifadesi, Benyon ve diğ. (2013) tarafından yapılan çalışmada dijital turizm ifadesi, Kayıkçı ve Bozkurt (2018) tarafından yapılan çalışmada turizmde dijital gelişmeler, Sünnetçioğlu (2019) tarafından yapılan çalışmada turizmde dijital dönüşüm şeklinde kullanılmıştır. Happ ve Horvath dijital turizm kavramını pazarlama odaklı yaklaşıma göre incelemiştir. Dijital turizm kavramının arz ve talep odaklı iki yönlü analiz ederken 7 P kavramları ile bütünleştirerek bir model oluşturmuştur. Oluşturulan modelde dijital turizmin gelişiminde etkili olan unsurlar yer almaktadır. Dijitalleşme örgüt içerisinde yönetim, pazarlama, insan kaynakları gibi birimlerde de yer alması gerekliliğine vurgu yapılmıştır. Dijital turizm daha çok yönetici konumunda olan departmanlara teşhir görseli, ürün satış1 sağlarken turistler için ise konaklama, yemek, transfer, alış veriş imkanı sunmaktadır. Dijital turizmin özelliklerini dijital, bütünlük gerçek zaman, nesnellik olarak tanımlamaktadır. Dijital turizmin özelliklerinden ilki olan dijital, coğrafi bilgi sistemi, uzaktan algılama, küresel navigasyon uydu sistemi, internet ve bilgi teknolojileri ile teknik destek kisminı oluşturmaktadır. Bütünlük, dijital turizm faaliyetlerinin tüm unsurlarını içeren, eksiksiz bir süreci kapsayan bilgisayar sistemlerini oluşturmaktadır. Gerçek zaman, dijital turizmde turizm bilgilerinin ve hizmetlerinin gerekli zamanlarda güncellenmesini, gerek hükümet, gerek girişimciler ve turistler için en güncel turizm trendlerini sağlamaktadır. Nesnellik, dijital turizm coğrafi bilgi sistemleri ile bilgisayar teknolojilerini etkin bir şekilde birleştirmekte ve coğrafi bilgi sistemlerine ilişkin net ve objektif veriler sunmaktadır $(\mathrm{Wu}, 2020)$.

Aşağıda yer alan Tablo 1'de Endüstri 4.0'ın turizm alanına getirmiş olduğu kavramlar ve bu kavramlar kapsamında ilişkilendirilen teknolojiler ile ilgili çalışmalar yer almaktadır.

Tablo 1. Kavramlar ve İlişkilendirilen Teknolojiler (Kaynak: Yazarlar tarafından oluşturulmuştur)

\begin{tabular}{ccc}
\hline Çalışmalar & Kavramlar ve İlişkilendirilen Teknolojiler & $\begin{array}{c}\text { Teknolojilerin } \\
\text { Kullanıldığı } \\
\text { Turizm Alanları }\end{array}$ \\
\hline Aykıllı Turizm (2021) & $\begin{array}{c}\text { Akıllı turizm kavramı bilgi ve iletişim } \\
\text { teknolojilerinin gelişmesi kapsamında } \\
\text { değerlendirilmiştir }\end{array}$ & Destinasyon \\
\hline Korkmaz (2021) & Akıllı turizm kavramı nesnelerin interneti ile \\
& ilişkilendirilmiştir & Destinasyon \\
\hline
\end{tabular}




\begin{tabular}{|c|c|c|}
\hline $\begin{array}{l}\text { Ağraş, Yıldız ve } \\
\text { Aktürk (2020) }\end{array}$ & $\begin{array}{l}\text { Akıllı turizm kavramı nesnelerin interneti ile } \\
\text { ilişkilendirilmiştir }\end{array}$ & Destinasyon \\
\hline $\begin{array}{c}\text { Ayyıldız ve } \\
\text { Ayyıldız (2020) }\end{array}$ & $\begin{array}{l}\text { Akıllı turizm iş modellerinin bilgi ve iletişim } \\
\text { teknolojileri ile bütünleşmesi ile ilişkilendirilmiştir. } \\
\text { Nesnelerin interneti, bulut bilişim, büyük veri gibi } \\
\text { teknolojilerin akıllı telefonlar, tablet, bilgisayar, } \\
\text { mikrofon, sensör gibi aracılarla sağlanması şeklinde } \\
\text { tanımlanmıştır }\end{array}$ & Destinasyon \\
\hline $\begin{array}{l}\text { Binbaşığlu } \\
\quad(2020)\end{array}$ & $\begin{array}{c}\text { Akıllı turizm kavramı web sitesi, mobil } \\
\text { uygulamalar, wifi, QR kodu, dokunmatik ekranlar, } \\
\text { kısa mesaj ve multimedya mesaj, çağrı merkezi, } \\
\text { akıllı rehber sistemi, akıllı kart, akıllı çevre, } \\
\text { kalabalık yönetimi, mobil ödeme, çevrimiçi } \\
\text { kuponlar, artırılmış gerçeklik, sanal seyahat gibi } \\
\text { çok sayıda unsuru kapsamaktadır }\end{array}$ & $\begin{array}{c}\text { Bibliyometrik } \\
\text { literatür taraması }\end{array}$ \\
\hline Ercan (2020) & Akıllı turizmde büyük veri kullanımı incelenmiştir & $\begin{array}{l}\text { Müşteri ilişkileri } \\
\text { yönetimi, } \\
\text { Destinasyon } \\
\text { yönetimi, } \\
\text { Talep tahminleme }\end{array}$ \\
\hline $\begin{array}{l}\text { Şimşek ve } \\
\text { Cinnioğlu (2020) }\end{array}$ & $\begin{array}{l}\text { Otellerdeki karekod uygulamaları akıllı turizm } \\
\text { kapsamında değerlendirilmiştir }\end{array}$ & Otel İşletmesi \\
\hline $\begin{array}{l}\text { Bahar, } \\
\text { Yüzbaşıŏlu ve } \\
\text { Topsakal (2019) }\end{array}$ & $\begin{array}{l}\text { Akıllı turizm kavramı içinde yer alan teknolojiler } \\
\text { yapay zeka, artırılmış gerçeklik gibi çeşitli bilgi ve } \\
\text { iletişim teknolojilerini kapsamaktadır }\end{array}$ & Turizm Rehberliği \\
\hline $\begin{array}{l}\text { Cabi ve Erbaşı } \\
\text { (2019) }\end{array}$ & $\begin{array}{l}\text { Akıllı turizm kavramı bilgi ve iletişim } \\
\text { teknolojilerinde yaşanan gelişmelerle birlikte alt } \\
\text { yapı olarak kullanılması ve iş süreçlerini, iş } \\
\text { performanslarını iyileştirmeye yönelik uygulamalar } \\
\text { şeklinde değerlendirilmiştir }\end{array}$ & Otel İşletmesi \\
\hline Ercan (2019) & Akıllı turizm teknolojileri & Otel İşletmesi \\
\hline $\begin{array}{l}\text { Karamustafa ve } \\
\text { Yilmaz (2019) }\end{array}$ & $\begin{array}{c}\text { Akıllı turizm nesnelerin interneti, mobil iletişim, } \\
\text { bulut bilişim ve yapay zeka teknolojileri ile } \\
\text { ilişkilendirilmiştir }\end{array}$ & Otel İşletmesi \\
\hline Yavuz (2019) & $\begin{array}{l}\text { Akıllı turizm kapsamında kullanılabilecek } \\
\text { teknolojiler olarak artırılmış gerçeklik, sanal } \\
\text { gerçeklik değerlendirilmiştir }\end{array}$ & Destinasyon \\
\hline Yilmaz (2019) & Akıllı turizm teknolojileri & Otel İşletmesi \\
\hline
\end{tabular}




\begin{tabular}{|c|c|c|}
\hline Ataman (2018) & $\begin{array}{l}\text { Akıllı turizmin unsurları doğal kaynaklar, yönetim, } \\
\text { turist ve işletmelerin yer aldığı bilgi işlem merkezi } \\
\text { ile birlikte yapay zeka, bulut bilişim ve nesnelerin } \\
\text { interneti olarak belirtilmiştir }\end{array}$ & Destinasyon \\
\hline $\begin{array}{l}\text { Başer ve Doğan } \\
\qquad(2018)\end{array}$ & $\begin{array}{l}\text { Akıllı turizm teknolojileri kapsamında bilgi ve } \\
\text { iletişim teknolojileri genel değerlendirilmiştir }\end{array}$ & Destinasyon \\
\hline Topsakal (2018) & $\begin{array}{c}\text { Akıllı turizm kapsamında nesnelerin interneti, } \\
\text { uygulamalar, artırılmış gerçeklik, yakın saha } \\
\text { iletişim değerlendirilmiştir }\end{array}$ & Turizm \\
\hline $\begin{array}{l}\text { Yalçınkaya, Atay } \\
\text { ve Karakaş (2018) }\end{array}$ & $\begin{array}{c}\text { Akıllı turizm uygulamalarında kullanılan } \\
\text { teknolojiler nesnelerin interneti, mobil iletişim, } \\
\text { bulut bilişim, yapay zekanın internet, sosyal medya } \\
\text { ve akıllı telefon aracılığı ile kullanımını } \\
\text { kapsamaktadır }\end{array}$ & $\begin{array}{l}\text { Destinasyon ve } \\
\text { Otel }\end{array}$ \\
\hline
\end{tabular}

\begin{tabular}{|c|c|c|}
\hline $\begin{array}{l}\text { Çelik ve Topsakal } \\
\text { (2017) }\end{array}$ & $\begin{array}{l}\text { Akıllı turizm kavramı bulut bilişim, büyük veri, } \\
\text { mobil uygulamalar, konuma dayalı hizmetler, } \\
\text { coğrafi etiket, sanal gerçeklik, akıllı teknolojiler ile } \\
\text { değerlendirilmiştir }\end{array}$ & Destinasyon \\
\hline \multicolumn{3}{|c|}{ Dijital Turizm } \\
\hline $\begin{array}{l}\text { Erkmen ve Güler } \\
\qquad(2020)\end{array}$ & $\begin{array}{c}\text { Turizmde dijitalleşme kavramı akıllı turizm ile } \\
\text { ilişkilendirilmiştir }\end{array}$ & Destinasyon \\
\hline $\begin{array}{l}\text { Hazarhun ve } \\
\text { Y1lmaz (2020) }\end{array}$ & $\begin{array}{l}\text { Restoranlarda dijital dönüşüm, robot garsonlar, } \\
\text { dijital menüler, nesnelerin interneti }\end{array}$ & Restoran \\
\hline Yavuz (2020) & $\begin{array}{l}\text { Turizmde dijital dönüşüm sürecinde yapay zeka, } \\
\text { büyük veri, bulut bilişim, nesnelerin interneti }\end{array}$ & Oteller \\
\hline $\begin{array}{l}\text { Bağçı ve İçöz } \\
\text { (2019) }\end{array}$ & $\begin{array}{c}\text { Turizmde dijitalleşme yapay zeka, nesnelerin } \\
\text { interneti, sanal gerçeklik, robotlar ve 3d yazıcılar } \\
\text { şeklinde değerlendirilmiştir }\end{array}$ & Z ve Alfa kuşağ \\
\hline
\end{tabular}

\begin{tabular}{ccc}
\hline $\begin{array}{c}\text { Sayın ve Karaman } \\
(2019)\end{array}$ & $\begin{array}{c}\text { Dijital turizm kapsamında bulut bilişim, artırılmış } \\
\text { gerçeklik, nesnelerin interneti, büyük veri, kripto } \\
\text { paralar, sosyal medya, robot teknolojiler, yapay } \\
\text { zeka ile ilişkilendirilmiştir }\end{array}$ & Turizm Sektörü \\
\hline $\begin{array}{c}\text { Sünnetçioğlu } \\
(2019)\end{array}$ & $\begin{array}{c}\text { Turizmde dijital dönüşüm, akıllı uygulamalar, } \\
\text { robotlar, mobil cihazlar, yapay zeka }\end{array}$ & Turizm sektörü \\
\hline $\begin{array}{c}\text { Kayıç̧ı ve } \\
\text { Bozkurt (2018) }\end{array}$ & Yapay zekanın turizm sektöründeki yansımaları \\
değerlendirilmiştir & Z ve Alfa kuşağ1 \\
\hline
\end{tabular}


Yildiz ve

Davutoğlu (2020)
Turizm 4.0'da yapay zeka, nesnelerin interneti, destinasyon yönetim sistemleri, merkezi

rezervasyon sistemleri, müşteri ilişkileri yönetimi, dijital telefon şebekeleri, akıllı otel yönetim sistemleri, sanal gerçeklik, mobil uygulamaları kapsamaktadır
Restoran

Turizm sektörü

Turizm 4.0 ile birlikte kullanılan teknolojiler büyük veri, nesnelerin interneti, karma gerçeklik, giyilebilir teknolojiler

\begin{tabular}{ccc}
\hline $\begin{array}{c}\text { Sayın ve Karaman } \\
(2019)\end{array}$ & $\begin{array}{c}\text { Turizm 4.0 kavramı kişiselleştirilmiş hizmetler, } \\
\text { verimli tedarik zinciri, akıllı çalışma ortamı, büyük } \\
\text { veri kullanımı ile ilişkilendirilmiştir }\end{array}$ & Turizm sektörü \\
\hline $\begin{array}{c}\text { Topsakal, } \\
\text { Yüzbaşığlu, } \\
\text { Çelik ve Bahar } \\
(2018)\end{array}$ & $\begin{array}{c}\text { Tünetim } 4.0 \text { da kullanılan teknolojiler akıllı otel } \\
\text { video izleme gibi nesnelerin interneti teknolojileri } \\
\text { değerlendirilmiştir }\end{array}$ & Turizm sektörü \\
\hline
\end{tabular}

Tablo 1'de Google schoolar veri tabanında akıllı turizm, dijital turizm ve turizm 4.0 yazılarak elde edilmiş olan çalışmalar yer almaktadır. Akıllı turizm kapsamında ulaşılabilen çalışmalarda akıllı turizm kavramı kapsamında değerlendirilen teknolojiler arasında karekod kullanımı, bulut bilişim, büyük veri, mobil uygulamalar, konuma dayalı hizmetler, coğrafi etiket, sanal gerçeklik, akıllı teknolojiler, nesnelerin interneti, yapay zeka, artırılmış gerçeklik, dokunmatik ekranlar, akıllı rehber sistemi yer almaktadır. Dijital turizm kavramı kapsamında değerlendirilen teknolojiler arasında ise yapay zeka, nesnelerin interneti, büyük veri, bulut bilişim, mobil cihazlar, akıllı uygulamalar, robotlar, kripto paralar, sosyal medya ile ilişkilendirilmiştir. Turizm 4.0 başlığı altında yapılan çalışmalarda ise akıllı sistemler, yapay zeka, nesnelerin interneti, mobil uygulamalar, karma gerçeklik, giyilebilir teknolojiler, büyük veri kullanımı ile ilişkilendirilmiştir.

Tablo 2. Kavramlar Kapsamında Kullanılan Teknolojiler (Kaynak: yazarlar tarafından oluşturulmuştur)

\begin{tabular}{cccc}
\hline Teknolojiler $\backslash$ Kavramlar & Akıllı Turizm & Dijital Turizm & Turizm 4.0 \\
\hline Nesnelerin İnterneti & + & + & + \\
\hline Yapay Zeka & + & + & + \\
\hline Bulut Bilişim & + & + & + \\
$\begin{array}{c}\text { Akıllı } \\
\text { Teknolojiler } \backslash \text { Cihazlar }\end{array}$ & + & + & + \\
\hline Büyük Veri & + & + & + \\
\hline
\end{tabular}




\begin{tabular}{cccc}
\hline $\begin{array}{c}\text { Sanal } \begin{array}{c}\text { Artırılmış } \backslash \text { Karma } \\
\text { Gerçeklik }\end{array} \\
\text { Mobil Uygulamalar }\end{array}$ & + & + & + \\
\hline Yakın Saha İletişimi & + & - & - \\
\hline
\end{tabular}

Tablo 2'de Google scholar veri tabanı tarama sonucu elde edilen çalışmalar kapsamında endüstri 4.0'ın turizm alanında ortay çıkarmış olduğu kavramlar başlığı altında değerlendirilen teknolojilerin neler olduğu görselleştirilmiştir. Akıllı turizm, dijital turizm ve turizm 4.0 kavramlarında kullanılan teknolojiler benzerlik göstermektedir. Ancak gerek yerli gerekse yabancı alan yazında daha detaylı içerik analizi şeklinde çalışmalara yapılarak kavramlar kapsamında değerlendirilmesi gereken teknolojilerin neler olduğu ortaya çıkarılabilir.

\section{SONUÇ VE ÖNERILER}

Geçmişten günümüze yaşanan sanayi devrimleri birçok sektörü farklı şekilde etkilemiş ve yeni terminolojiler getirmiştir. Son endüstri devrimi olan Endüstri 4.0 ile turizm sektöründe farklı turizm kavramları (akıllı turizm, dijital turizm, turizm 4.0) ortaya çıkmıştır. Bu kavramlar yapılan akademik çalışmalarda sıklıkla kullanılmaya başlanmış ve bazen de birbiri yerine kullanıldığı görülmüştür. Buradan hareketle bu çalışmada bahsi geçen kavramlar ile ilgili derinlemesine araştırma yapılmış ve her bir kavramın farklı çalışmalarda nasıl ele alındığı ortaya konulmaya çalışılmıştır.

Akıllı turizm ile ilgili çalışmalarda Endüstri 4.0'ın ortaya koymuş olduğu yeni teknolojiler olan bulut bilişim, büyük veri, artırılmış gerçeklik, sanal gerçeklik, yapay zeka, nesnelerin interneti gibi gelişmelerin turizm sektörünün farklı dallarında uygulanması konusu ele alınmıştır. Akıllı turizm denildiğinde turistin ihtiyaç ve beklentilerinin karşılandığı, çevrim içi iş modelinin kullanıldığı, merkezinde bilgi değişim sisteminin yer aldığı ve bunları yaparken yapay zeka, büyük veri, internete bağlanan nesneler ve bulut bilişimden yararlanılan sistemlerin bütünü olarak ortaya çıkan bütüncül bir kavramı kapsamaktadır. Akıllı turizmde verilerin gelişmiş teknolojilerle toplanması, kullanılması ve turizme uyum sağlayacak şekilde kullanılması esastir.

Dijital turizm kavramı başlığı altında yapılan çalışmalarda bulut bilişim, nesnelerin interneti, yapay zeka, mobil cihazlar, robot teknolojiler, sanal gerçeklik gibi teknolojiler değerlendirilmiştir. Dijital turizm kavramının kullanımına bakıldığında akıllı turizmdeki teknolojilerle benzerlik göstermektedir. Dijital kavramı aslında bir dönüşümü ifade etmektedir. Öncelerde fiziksel olarak toplanan farklı büyüklükteki farklı verilerin günümüzde akıllı telefonlar, bilgisayarlar, robotlar, sensörler aracılığ ile kullanımı sonucu dijital ortam var olmuştur. Özellikle büyük veri ile yakından ilişkili olan dijital kavramının turizm için kullanılacak olan büyük verinin teknolojik 8araçlar ile yapılması açısından dönüşüm ya da süreç olarak değerlendirilmesi daha uygun olmaktadır.

Turizm 4.0 ise çalışmalarda nesnelerin interneti, sanal gerçeklik, giyilebilir teknolojiler, akıllı sistemler gibi uygulamaları kapsamaktadır. Endüstri 4.0 kavramının genel olarak turizm alan yazınındaki karşılığı olarak Turizm 4.0 kavramının ortaya çıktığı ileri sürülebilir. Endüstri 4.0 ile ortaya çıkan teknolojilerin turizmde kullanılıyor olması Turizm 4.0 kavramını ortaya 
koyarken akıllı turizm kavramı ile aynı teknolojileri kullanmaktadır. Söz konusu kavramlar her ne kadar birbiri ile karıştırılmış gibi görünse de her bir kavramın kapsam alanı bellidir. Akıllı turizm kapsamı akıllı başlığı altındaki uygulamaların turizmde bütünleşmiş hali olduğu söylenebilir. Dijital turizm ise iş süreçlerinde büyük verilerin kullanımının teknolojik araçlar ile yapılmasını sağlayarak süreci tanımlamaktadır. Turizm 4.0 ise endüstri 4.0 kavramının turizm alan yazınındaki adı olduğu söylenebilir.

$\mathrm{Bu}$ çalışmada alan yazın taraması sadece 'google scholar' veri tabanındaki çalışmaları ve endüstri 4.0'ın turizmde ortaya çıkardığ 1 'akıllı turizm, dijital turizm ve turizm 4.0' kavramlarını kapsamaktadır. Dolayısı ile ileriki çalışmalarda farklı veri tabanları konu ile ilgili taranarak bahsi geçen kavramların ele alınış biçimleri karşılaştırılabilir. Özellikle Türkiye'de konu ile ilgili yapılan çalışmalar ile yurtdışında yapılan çalışmalarda bahsi geçen kavramların tam olarak neyi ifade ettiği ve hangi teknolojiler ile birlikte ele alındığı karşılaştırılabilir. Bu sayede endüstri 4.0 ile turizmde ortaya çıan turizm kavramlarındaki kavram karmaşasının olup olmadığı ortaya konulup bu kavramların doğru şekilde kullanımı ve bilimsel çalışmalarda doğru şekilde ele alınması sağlanmış olacaktır.

\section{KAYNAKÇA}

Adeola, O. ve Evans, O. (2019). Digital tourism: mobile phones, internet and tourism in Africa. Tourism Recreation Research, 44(2), 190-202.

Ağraş, S, Yıldız, A. ve Aktürk, E . (2020). Akıllı turizmin Türkiye'de uygulanabilirliği: İstanbul örneği. Bartın Üniversitesi İktisadi ve İdari Bilimler Fakültesi Dergisi, 11(21), 207-231.

Akkuşcu, H. İ. (2019). Endüstri 4.0'ın çalışma hayatına etkisi: Bursa örneği. Yayımlanmamış yüksek lisans tezi, Bursa Uludağ Üniversitesi, Bursa.

Aksu, H. (2018). Dijitopya dijital dönüşüm yolculuk rehberi. İstanbul: Pusula Yayıncılık.

Alexis, P. (2017). R- Tourism: introducing the potential impact of robotics and service automation in tourism. 'Ovidius' University Annals, Economic Sciences Series, 0, 1, 211 216.

Ashton, K. (2009). That 'Internet of things' thing. RFID Journal 27 Mayss 2021 tarihinde https://www.rfidjournal.com/articles/pdf?4986 adresinden erişildi.

Ataman, H. (2018). Akıll turizm ve akıll destinasyonlar: Adremit körfezi'ne yönelik bir uygulama. Yayımlanmamış yüksek lisans tezi, Balıkesir Üniversitesi Sosyal Bilimler Enstitüsü Balıkesir.

Aykın, M.S. (2021). Avrupa birliği turizm politikası çerçevesinde Avrupa akıllı turizm başkentleri. Journal of Tourism Intelligence and Smartness, 4(1), 1-18. 
Babu, S.R. ve Subramoniam, S. (2016). Tourism management in internet of things era. Journal of IT and Economic Development, 7(1),1-14.

Bağçı, E. ve İçöz, O. (2019). Z ve alfa kuşağı ile dijitalleşen turizm. Güncel Turizm Araştırmaları Dergisi, 3(2), 232-256.

Bahar, M., Yüzbaşıŏlu, N. ve Topsakal, Y. (2019). Akıllı turizm ve süper akıllı turist kavramları 1şığında geleceğin turizm rehberliğine bakış. Aydın Adnan Menderes Üniversitesi Seyahat ve turizm Araştırmaları Dergisi, 14, 72-93.

Bal, G. ve İçten, T. (2017). Artırılmış gerçeklik teknolojisi üzerine yapılan akademik çalışmaların içerik analizi. Bilişim Teknolojileri Dergisi, 10(4), 401-415.

Banger, G. (2018). Endüstri 4.0 ve akıllı işletme. Eskişehir: Dorlion Yayın Evi.

Başer, G. ve Doğan O. (2018). Future trends fors mart tourism sestinations: case of Antalya. 1. Uluslararası Turizmde Yeni Jenerasyonlar ve Yeni Trendler Kongresi, Sapanca.

Benyon, D., Quigley, A., O'Keefe, B. ve Riva, G. (2014): Presence and digital tourism. AI $\mathcal{E}$ Society, 29(4), 521-529.

Bilgi Teknolojileri ve İletişim Kurumu (BTK) (2013). Bulut Bilişim. 12 Mayıs 2021 tarihinde https:// www.btk.gov.tr/uploads/pages/slug/bulut-bilisim.pdf adresinden erişildi.

Buhalis, D. (2003). ETourism: Information technology for strategic tourism management. London: Financial Times Prentice Hall.

Buhalis, D., ve Amaranggana, A. (2014). Smart tourism destinations. Information and Communication Technologies in Tourism, 553-564.

Burak, M.İ.L., \& Dirican, C. (2018). Endüstri 4.0 teknolojileri ve turizme etkileri. Disiplinlerarası Akademik Turizm Dergisi, 3(1), 1-9.

Cabi, A. ve Erbaşı, A. (2019). Akıllı turizm bağlamında akıllı otel işletmesi endeksi ve uygulaması. Konya: Sami Billur Yayıncılık.

Cohen, B. (2012). Smart cities Hub. 3 Nisan 2021 tarihinde http://smartcityhub.com/ adresinden erişildi.

Çelik, P. ve Topsakal, Y. (2019). Endüstri 4.0 ve akıllı turizm. Ankara: Detay Yayıncılık.

Çelik, P. ve Topsakal, Y. (2017). Akıllı turizm destinasyonları: Antalya destinasyonunun akıllı turizm uygulamalarının incelenmesi. Seyahat ve Otel İşletmeciliği Dergisi, 14(3), 149-166.

Çetinkaya, F.Ö. (2019). Sosyal medya ve turizm. Turizm 4.0 içinde. Ankara: Detay Yayıncılık.

Durrant A, Golembewski M, Kirk D, Benford S, Fischer J, Rowland D, ve McAuley D (2011). Automics: souvenir generating photoware for theme parks. In Proceedings of the 2011 annual conference on Human factors in computing systems (CHI '11). 1767-1776. ACM, New York.

Ercan, F. (2019). Smart tourism technologies: appl,cations in hotel business. Eds. Krystev, V., Efe, R. \& Atasoy, E.. Theory and practice in social sciences içinde. Sofia: St. Kliment Ohridski University Press. 
Ercan, F. (2020). Akıllı turizmde büyük veri kullanımı: Sistematik bir derleme. OPUSUluslararası Toplum Araştırmaları Dergisi, 16(32), 5230-5249.

Erkmen, B. ve Güler Gönenç, E. (2020). Turizm ve dijitalleşme: Haskovo-Edirne kültürel ve tarihi destinasyonlar projesi örneği. Tourism and Recreation, 2(1), 111-118.

Fang, F. (2016). Atomic and close-to-atomic scale manufacturing-a trend in manufacturing development. Frontiers of Mechanical Engineering, 11(4), 325-327.

Fırat, O. Z. ve Fırat, S. Ü. (2017). Endüstri 4.0 yolculuğunda trendler ve robotlar. İstanbul Üniversitesi İsletme Fakültesi Dergisi, 46(2), 211-223.

Frederick, D. E. (2016). Libraries, data and the fourth industrial revolution (Data Deluge Column). Library Hi Tech News, 9-12.

Gretzel, U., Sigala, M., Xiang, Z., ve Koo, C. (2015). Smart tourism: Foundations and developments. Electronic Markets, 3(25), 179- 188.

Gretzel, U., Werthner, H., Koo, C., ve Lamsfus, C. (2015). Conceptual foundations for understanding smart tourism ecosystems. Computers in Human Behaviour, 50, 558563.

Gülcemal, T., Sayın, K. ve Karaman, A. (2019). Kripto paralar ve turizm. Eds. Karaman, A. ve Sayın, K. Dijital turizm sektörün yeni geleceği içinde. Konya: Eğitim Yayınevi.

Happ, E. ve Horvath, Z. İ. (2018). Digital tourism is the challenge of future- a new approach to tourism. Knowledge Horizons- Economics, 10(2), 9-16.

Hazarhun, E. ve Yılmaz D. Ö. (2020). Restoranlarda dijital dönüşüm: Touch restoran örneği. Gastoria: Journal of Gastronomy and Travel Research, 4(3), 384-399.

Hermann, M., Pentek, T. ve Otto, B. (2016). Design principles for industry 4.0 Scenorios. Proceeding of The Annual Hawaii International Conference on System Scienes.

Karaman, A. ve Sayın, K. (2019). Dijital turizm sektörün yeni geleceği. Konya: Eğitim Yayınevi.

Karamustafa, K. ve Yılmaz, M. (2019). Konaklama işletmeleri yöneticilerinin akıllı turizm teknolojilerinin olası faydalarına yönelik algılarının değerlendirilmesi. Journal of Tourism and Gastronomy Studies, 7(3), 1669-1688.

Kayıkçı, Y. M. ve Bozkurt, K. A. (2018). Dijital çağda z ve alpha kuşağı, yapay zeka uygulamaları ve turizme yansımaları. Sosyal Bilimler Metinleri, 1, 54-64.

Kemer, E. (2021). Eğitim seviyesinin Endüstri 4.0 farkındalığına etkisi: Konaklama işletmelerinde bir uygulama. Türk Turizm Araştırmaları Dergisi, 5(2), 1138-1149.

Korkmaz, H.U. (2021). Akıllı turizmde kültürel miras ve yaratıcılık: Konya üzerine nitel bir araştırma. Journal of Vocational and Social Sciences of Turkey, 5, 132-143.

Kurgun, O. A. (2019). Küresel turizm ekosistemi ve turizm 4.0. Eds. Kurgun, H. Ve Kurgun O. A. Turizm 4.0 kavramlar ve uygulamalar içinde. Ankara: Detay Yayıncilık.

Law, R., Chan, I. C. C., ve Wang, L. (2018). A comprehensive review of mobile technology use in hospitality and tourism. Journal of Hospitality Marketing $\mathcal{E}$ Management, 27(6), 626-648. 
Li, J., Bon, M. A. ve Ye, B. H. (2019). Hotel employee's artificial intelligence and robotics awareness and its impact on turnover intention: The moderating roles of perceived organizational support and competitive psychological climate. Tourism Management, $73,172-181$.

Li, Y., Hu, C., Huang, C. ve Duan, C. (2017). The concept of smart tourism in the context of tourism information services. Tourism Management, 58, 293-300.

MacDougall, W. (2013). Industrie 4.0: Smart manufacturing for the future, Germany trade and invest, Berlin.

Masseno, M. D. ve Santos, C. (2018). Smart tourism destinations prilvacy risks on data protection. Revista Electronica Sapere Aude, 1(1), 125-149.

Mehraliyev, F., Choi, Y, ve Köseoglu, M. A. (2019). The progress on smart tourism research. Journal of Hospitality and Tourism Technology, 9(3), 522-538.

Mil, B. ve Dirican, C. (2018). Endüstri 4.0 teknolojileri ve turizme etkileri. Disiplinlerarası Akademik Turizm Dergisi, 1(3), 1-9.

Osawa, H., Ema., AHattori, H., Akiya, N., Kanzaki, N., Kubo, A., Koyama, T., Ichise, R. (2017). Analysis of robot hotel: reconstruction of works with robots. 26th IEEE International Symposium on Robot and Human Interactive Communication (RO-MAN) Lisbon, Portugal, Aug 28-Sept 1, 2017. 5 May1s 2021 tarihinde https://ieeexplore.ieee.org/stamp/stamp.jsp?tp=\&arnumber $=8172305 \quad$ adresinden erişildi.

Özdoğan, O. (2017). Endüstri 4.0: Dördüncü sanayi devrimi ve endüstriyel dönüşümün anahtarlarn. İstanbul: Pusula Yayıncilık.

Özsoylu A. F. (2017). Endüstri 4.0. Çukurova üniversitesi İİBF Dergisi, 21(1), 41-64.

Pamuk, N.S. ve Soysal, M. (2018). Yeni sanayi devrimi endüstri 4.0 üzerine bir inceleme. Verimlilik Dergisi, (1), 41-66.

Pieskä, S., Luimula, M., Jauhiainen, J. ve Spiz, V. (2012). Social service robots in public and private environments. Recent Researches in Circuits, Systems, Multimedia and Automatic Control, 190-196.

Sağır, M. ve Oraç, E. (2019). İşletmelerde yapay zeka uygulamaları; turizm incelemesi. Eds. Karaman, A. ve Sayın, K. Dijital turizm sektörün yeni geleceği içinde. Konya: Eğitim Yayınevi.

Sayın, K. ve Karaman, A. (2019). Endüstri 4.0 ve turizm 4.0 arasındaki ilişki. Eds. Karaman, A. ve Sayın, K. Dijital turizm sektörün yeni geleceği içinde. Konya: Eğitim Yayınevi.

Sunar, H., Ateş, A. ve Akmeşe, K. A. (2019). Arttırılmış gerçeklik ve turizm 4.0. Eds. Karaman, A. ve Sayın, K. Dijital turizm sektörün yeni geleceği içinde. Konya: Eğitim Yayınevi.

Sünnetçioğlu, S. (2019). Turizmde dijital dönüşüm ve turist yerli halk ilişkileri: eleştirel bir yaklaşım. 3. Uluslararası Turizmin Geleceği Kongresi Bildiri Kitabı. 26-28 Eylül 2019, Mersin. 
Soydaş, M. E. ve Saçlı, Ç. (2019). Büyük veri ve turizm 4.0. Eds. Karaman, A. ve Sayın, K. Dijital turizm sektörün yeni geleceği içinde. Konya: Eğitim Yayınevi.

Şekkeli, Z. H., \& Bakan, İ. (2018). Endüstri 4.0'in etkisiyle lojistik 4.0. Journal of Life Economics, 5(2), 17-36.

Şimşek, E. ve Cinnioğlu, H. (2020). Akıllı turizm destinasyonlarındaki otellerin karekod kullanımı: İstanbul smart Beyoğlu üzerine bir araştırma. Uluslararası Yönetim İşletme ve İktisad Dergisi, 16(3), 675-690.

Türk Dil Kurumu (TDK). (2021). 1 Nisan 2021 tarihinde https://sozluk.gov.tr/ adresinden erişildi.

Topsakal, Y. (2018). Akıllı turizm kapsamında engelli dostu mobil hizmetler: Türkiye turizm için öneriler. Journal of Tourism Intelligence and Smartness, 1(1), 1-13.

Topsakal, Y., Yüzbaşığlu, N., Çelik, P. ve Bahar, M. (2018). Turizm 4.0 - turist 5.0: İnsan devriminin neden endüstri devrimlerinden bir numara öne olduğuna ilişkin bakış. Journal of Tourism Intelligence and Smartness, 1(2), 1-11.

Verl, A. (2017). Robotics \& Industrie 4.0. IFR- International Federation of Robotics. 15 Haziran 2021 tarihinde https://ifr.org/ adresinden erişildi.

Wu, W. (2020). Analysis of digital tourism, virtual tourism and wisdom tourism. Eds. Xu, Z., Parizi, R. M., Hammoudeh, M., Layola-Gonzales, O. Cyber security intelligence and analiytcs içinde. Berlin: Springer.

Yalçınkaya, P., Atay, L. ve Karakaş, E. (2018). Akıllı turizm uygulamaları. Gastoria: Journal of Gastronomy and Travel Research, 2(2), 34-52.

Yavuz, A. (2020). Turizmde dijital dönüşüm: Otel yöneticilerinin bakış açılarının incelenmesi. Yayımlanmamış yüksek lisans tezi, Düzce Üniversitesi Sosyal Bilimler Enstitüsü, Düzce.

Yavuz, M. C. (2019). Smart destination: Tourism, innovation, entrepreneurship, challenges. Journal of Tourism Theory and Research, 5(2), 203-211.

Yazıcı, S. ve Ayazlar, G. (2019). Bulut bilişim ve turizm 4.0. Eds. Karaman, A. ve Sayın, K. Dijital turizm sektörün yeni geleceği içinde. Konya: Eğitim Yayınevi.

Yıldız, E. ve Davutoğlu, A. N. (2020). Turizm 4.0'dan gastronomi 4.0' giden yolda: Geleceğin restoranları ve yönetimi. Akademik Sosyal Araştırmalar Dergisi, 8(109), 301-318. 